\title{
UNIVERSITY OF LEEDS
}

This is a repository copy of Working together to deliver stratified medicine research effectively.

White Rose Research Online URL for this paper:

http://eprints.whiterose.ac.uk/143456/

Version: Accepted Version

\section{Article:}

Attar, SG, Poustie, VJ, Smye, SW orcid.org/0000-0003-4975-5220 et al. (6 more authors) (2019) Working together to deliver stratified medicine research effectively. British Medical Bulletin, 129 (1). pp. 107-116. ISSN 0007-1420

https://doi.org/10.1093/bmb/ldz003

(c) 2019, The Author(s). Published by Oxford University Press. All rights reserved. For permissions, please e-mail: journals.permissions@oup.com This article is published and distributed under the terms of the Oxford University Press, Standard Journals Publication Model

(https://academic.oup.com/journals/pages/open_access/funder_policies/chorus/standard publication_model).

\section{Reuse}

Items deposited in White Rose Research Online are protected by copyright, with all rights reserved unless indicated otherwise. They may be downloaded and/or printed for private study, or other acts as permitted by national copyright laws. The publisher or other rights holders may allow further reproduction and re-use of the full text version. This is indicated by the licence information on the White Rose Research Online record for the item.

\section{Takedown}

If you consider content in White Rose Research Online to be in breach of UK law, please notify us by emailing eprints@whiterose.ac.uk including the URL of the record and the reason for the withdrawal request. 


\title{
Working together to deliver Stratified Medicine research effectively
}

S.G. Attar ${ }^{1}$ V.J. Poustie ${ }^{1,2}$, S.W. Smye ${ }^{2}$, J.M. Beety ${ }^{2}$,D.B. Hawcutt ${ }^{1}$, S. Littlewood ${ }^{2}$, L. Oni ${ }^{1}$, M. Pirmohamed ${ }^{* 1}$, M.W. Beresford ${ }^{* 1,2}$. *Joint Senior authors

1. Institute of Translational Medicine, University of Liverpool, Liverpool, UK; 2. NIHR Clinical Research Network (CRN) Coordinating Centre

Corresponding author: Dr V.J. Poustie

Institute in the Park, Alder Hey Children's NHS Foundation Trust,

Liverpool, L14 5AB

Tel: 00441512824533

v.poustie@liverpool.ac.uk

Short Title: Delivering stratified medicine research

\begin{abstract}
Introduction or background

Stratified medicine is an important area of research across all clinical specialties, with far reaching impact in many spheres. Despite recently formulated global policy and research programmes, major challenges for delivering stratified medicine studies persist. Across the globe, clinical research infrastructures have been set up to facilitate high quality clinical research.
\end{abstract}

\section{Sources of data}

This article reviews the literature and summarises views collated from a workshop held by the UK Pharmacogenetics and Stratified Medicine Network and the NIHR Clinical Research Network in November 2016.

\section{Areas of agreement}

Stratified medicine is an important area of clinical research and health policy, benefitting from substantial international, cross-sector investment and has the potential to transform patient care. However there are significant challenges to the delivery of stratified medicine studies.

\section{Areas of controversy}

Complex methodology and lack of consistency of definition and agreement on key approaches to the design, regulation and delivery of research contribute to these challenges and would benefit from greater focus.

\section{Growing points}

Effective partnership and development of consistent approaches to the key factors relating to stratified medicine research is required to help overcome these challenges.

\section{Areas timely for developing research}

This paper examines the critical contribution clinical research networks can make to the delivery of national (and international) initiatives in the field of stratified medicine. Importantly, it examines the position of clinical research in stratified medicine at a time when pressures on the clinical and social services are mounting.

\section{Keywords (3 - 10 words)}

Stratified Medicine, Personalised Medicine, Precision Medicine, Clinical Research Networks 


\section{Background}

Stratified medicine, providing the right patient with the right drug at the right dose at the right time, is widely recognised to be of huge potential global benefit. ${ }^{1,2,3}$ Also termed personalised or precision medicine, ${ }^{3,4}$ stratification is undertaken to better direct therapy to gain a deeper understanding of the differing mechanisms of disease and treatment responses. Stratified medicine has become an important area of medical research across all clinical specialties, with far reaching impact in health economic, societal, political and industrial spheres. ${ }^{5}$ In the treatment of cancer, it is already being implemented based on molecular changes in the somatic genome and is leading to a step-change in care, not only in the use of targeted drugs but also in the use of the same drugs across different cancers with the same mutations. ${ }^{6}$ For example the $B R A F$ mutation, first identified in malignant melanoma, has also been identified in other malignancies, for instance hairy cell leukemia, and has led to the use of vemurafenib for these two apparently disparate malignant conditions. ${ }^{7}$

Healthcare providers in many countries including United Kingdom (UK), USA, Canada, Australia, China and India have proactively formulated policy and research programmes in this field with substantial investments. ${ }^{8-}$ ${ }^{12}$ The precision medicine initiative (PMI), launched by former US President Obama in his State of the Union address in January 2015, with a budget of $\$ 215$ million, gave significant momentum to these efforts. ${ }^{2,13}$ The European Union-funded 'PerMed' project is developing a European strategy framework for personalised medicine. $^{14}$

Across EU Member States, many key initiatives have been launched to support stratified medicine research and implementation. ${ }^{15,16}$ In the UK, the National Institute for Health Research (NIHR), the Medical Research Council (MRC), the Academy of Medical Sciences, Innovate UK and the Association of British Pharmaceutical Industries (ABPI), NHS England and others, have led a series of such initiatives, including workshops, conferences and reports on stratified medicine. Many of these outline key recommendations and highlight future programmes that must address the urgent need to develop robust new approaches through to implementation of stratified medicine at scale in clinical practice. ${ }^{17-20}$

In parallel, clinical research networks have been set up worldwide to facilitate the delivery of clinical trials . ${ }^{21-}$ ${ }^{25}$ Established networks streamline and coordinate research activities providing efficiency for sponsors of trials, ${ }^{26}$ benefit to investigators ${ }^{27}$ and availing patients and the public opportunities to participate in clinical research. $^{28,29}$

This paper explores challenges for delivering stratified medicine studies. Reviewing the perspectives and challenges from the many key stakeholders involved in this process, it demonstrates the critical contribution clinical research networks make to the successful delivery of national (and international) initiatives in the field. Importantly, it examines the position of clinical research in stratified medicine at a time when pressures on clinical and social services are mounting in many countries.

\section{Stakeholders in stratified medicine The Patient and Researcher}

Failure to recognise and integrate the needs of patients in research, from study design and delivery, to implementation of the study's findings, renders stratified medicine studies very challenging and at times 
impossible to achieve. Excellent examples where patients and public have been an integral part of development through to adoption of new medical innovations exist. ${ }^{29}$ For instance, a survey of patient involvement in studies run through the MRC Clinical Trials Unit suggests that consumer involvement had multiple benefits to the design and quality of the studies, the recruitment, and dissemination of findings. ${ }^{30}$ Major improvements have been made in effective engagement and partnership with patients and the wider public in the design and delivery of clinical studies/trials at organisational as well as an individual trial level. ${ }^{31}$ However, internationally this role remains variable and a structured, appropriate and consistent approach is required. . $32-34^{3}$

Within stratified medicine research, this issue is further compounded by all too frequent inconsistencies in nomenclature and misunderstanding of the concepts underpinning the field. Important partnerships and initiatives have started to address how individual patients and the public in general, understand and respond to the concept of stratified medicine. ${ }^{35}$ Having a clear, consistent definition remains a basic challenge for stratified medicine. ${ }^{35}$

Interpretation of terminology used may also conjure negative perceptions of equality and impact on participation. The challenge for these studies is that often many patients need to be screened to identify a small proportion of people with the relevant biomarkers. For example, $A L K$ mutations in lung cancer are only present in $3 \%$ of patients, which means that many people approached were not suitable to participate in the ALK inhibitor trial. ${ }^{36}$ This can easily present a barrier to involvement by patients who may worry that they have a form of disease where there is no treatment option, thereby creating therapeutic orphans, something which needs to be considered in all disease areas. For these reasons, novel ways are being developed to overcome this; for example, umbrella trials, multi-arm, multi-biomarker trials where the drug choice is dependent on the biomarker are becoming more common. ${ }^{37}$ Any study design should take into account the effect of the treatment to those who do not have any of the specific biomarkers, which provides a more inclusive research design for the patient. ${ }^{38}$

In pharmacogenomic studies, sample size is dependent on the population frequency of the allele of interest, and its effect size. This can lead to problems identifying adequate numbers of patients exposed to the drug of interest - for example, in a prospective cohort study of carbamazepine patients, 4855 subjects were recruited to identify 372 who carried the risk $H L A-B * 15: 02$ allele. ${ }^{39}$ The requirement of large sample sizes for rare phenotypes, for example for serious adverse drug reactions, can be problematical for the researcher in trying to identify a large enough sample of accurately phenotyped patients. Where pharmacogenomic variants can determine dose requirement, a validated algorithm may determine the success or otherwise of a trial, and small differences in the algorithm can lead to marked changes in trial outcomes, as witnessed with warfarin. ${ }^{40}$

Open debate about key issues, providing relevant and accurate information and clarifying patients' concerns is key to progress here. Advancing public and patient engagement initiatives through specialty specific organisations can help provide access to patients and communicate research opportunities and findings. ${ }^{41}$ Assimilation with wider patient and public engagement initiatives has already commenced to unify work across regulatory, clinical and research settings which is important for stratified medicine. ${ }^{42-44}$ 
Development and delivery of stratified medicine studies involves a wide range of disciplines and perspectives, irrespective of whether the study is led from within the life sciences industry or academia. The research workforce no longer constitutes only the traditional clinician investigators, clinical nurses and data collection and entry staff who work across clinical trials within clinical settings. ${ }^{28,45}$ Stratified medicine studies take place in a wide variety of clinical environments, within and outwith the hospital inpatient or outpatient context. Studies may take place in patients' homes, in primary care, or in specific translational and/or experimental research units. For industry sponsored studies, although the funding and design of the trial may come from the company, delivery of the study will still depend on staff and facilities within the healthcare setting. In the UK, these include NIHR Biomedical Research Centres, Clinical Research Facilities and a wide range of other clinical research infrastructure resources. ${ }^{46}$ Research training and education, does not currently address this wider community of professionals. These span multiple sectors within and outwith hospitals, including biostatisticians, basic scientists, analysts and data-miners who may have limited experience within the clinical research environment. ${ }^{47}$

Identifying the workforce involved requires careful mapping of the activity of these studies/trials to the clinical context of delivery. It needs a careful understanding of the breadth and the scope of the infrastructures involved in the delivery of stratified medicine research, which is often not sub-specialty specific, and which spans diagnostics through to treatment intervention and involves multiple disciplines in its approach ${ }^{48}$ Clinical and research staff training needs to include supporting patients to make sound treatment decisions in this field. ${ }^{37}$ There is a need to develop cross-disciplinary training which is a challenge given the lack of appropriatelytrained staff in fields such as bioinformatics. ${ }^{49,50}$

Clinical research networks, including the NIHR Clinical Research Network in the UK, along with other research delivery infrastructures, are uniquely placed through their focus on training and education, to take a lead role to identify and map the expertise and training requirements to support effective delivery of stratified medicine across a wide range of clinical environments. ${ }^{51}$ Together, they can impact significantly on raising awareness and leading programmes that deliver a priority focus for appropriate training with continued engagement activities to support the needs and developments of these key components of the stratified medicine workforce. ${ }^{52}$

\section{NIHR Clinical Network Support for the ASTRAL 3 Trial $^{53}$}

The ASTRAL 3 trial was a multicentre international trial exploring treatment options for patients with a particular genotype of hepatitis $\mathrm{C}$ virus (HCV). Patients with HCV genotype 3, one of the most common types in the UK, were randomised to receive either a combination of sofasbuvir and velpatasvir for 12 weeks or 24 weeks of sofasbuvir and ribavirin (standard treatment). Randomisation was stratified according to whether or not cirrhosis was present at screening, and previous treatment status. A total of 277 patients were recruited to the treatment arm, and 275 to the control arm. The study found the new treatment regimen to be more effective than previous regimens and the results have been incorporated into treatment guidelines for the condition.

The NIHR Clinical Research Network supported the delivery of this commercially-sponsored study by facilitating study set up at the $10 \mathrm{UK}$ sites, provision of funded research nurse time, and contributed to the screening and recruitment of patients. 


\section{The Science}

Whilst randomised clinical trials (RCTs) remain the gold standard of evidence for the benefit of new therapeutics, standard trial designs may not be possible, appropriate or efficient in the development of new drugs, repurposing of old drugs, or in the development of biomarkers for off-patent drugs. This applies to nonpharmacological interventions as well including those using advances in digital technologies. ${ }^{54-56}$

Trials investigating one biomarker/drug pairing at a time, are inefficient, ${ }^{45}$ particularly when the biomarker has a low prevalence in the population with disease. Umbrella trial adaptive designs represent an opportunity to undertake multi-arm, multi-biomarker trials, but there are some statistical challenges. These trial designs offer adaptability to evolving knowledge about the biomarker(s) and drug(s) being tested.

The FOCUS4 trial was designed to overcome some of these challenges..$^{38}$ It is an integrated trial programme of parallel, molecularly stratified, and randomised comparisons of maintenance therapies for patients with advanced or metastatic colorectal cancer after receiving $1^{\text {st }}$-line chemotherapy; it includes a platform for recruiting almost all potential patients with colorectal cancer in a biomarker-driven trial, regardless of biomarker status. It has an "umbrella design" - a stratified trial design with nested, virtually separate, parallel RCTs for biomarker-defined subgroups of patients, each with its own appropriate control. Each of these, a separate randomised phase II/III trial, could stop early for lack of benefit or continue to its final stages.

Clinical research networks offer a unique breadth and reach for recruiting patients either nationally or across disease-specific contexts internationally. Patient-centric approaches to trial designs are important, for example to deliver trials close to where the patient is in the community, ${ }^{57}$ through digital connectivity, ${ }^{58}$ through local hubs that have research workforces that cover regional areas rather than the traditional settings of clinics and wards, ${ }^{59}$ as well as recruiting to rare diseases (nationally and internationally) effectively and in a timely manner ${ }^{60}$.

\section{The Infrastructure}

\section{$\underline{\text { Regulations }}$}

Stratified medicine has tremendous potential to utilise trial designs in an innovative and iterative way to benefit patients. Clinical research infrastructure and procedures may not currently be optimised to deliver these benefits to patients in similar innovative style. ${ }^{61,62}$ National regulatory procedures are generally designed for a single drug/intervention at multiple sites. In response to the progress and importance of a streamlined approach to overcoming the many barriers to safe and effective regulation of clinical research, regulatory bodies are working to consider novel approaches to evaluation of stratified medicine studies. For example, the UK's Health Research Authority has an explicit ambition "...to protect and promote the interests of patients and the public in health research, and to streamline the regulation of research". ${ }^{63}$ This may include accepting different levels of evidence to give approval for medicines, diagnostics or other types of interventions. A proportionate approach which protects public health whilst ensuring that regulation does not stifle innovation is crucial, and requires wide discussion amongst multiple stakeholders. A good example of this which is of particular importance to stratified medicine is the Wellcome Trust's setting up of an independent patient data taskforce, which aims to "support better conversations about the uses of health information, and to provide objective evidence about how and why patient data can be used for care and research". ${ }^{64}$ 


\section{Data and digital platforms}

Many emerging sources of 'big data' have created an opportunity to transform medical science. Research methodologies and tools are being developed to manage, analyse, visualise, and extract information from large, diverse, complex, longitudinal, and/or distributed biological, biomedical and healthy data sets to support stratified medicine. ${ }^{65}$ Existing systems, however, require effective mechanisms for storing and linking data. ${ }^{66}$ This requires improved standardisation for the collection, storage, and sharing of samples. ${ }^{67}$ Procedures for informed consent, future use of samples, potential of sample withdrawal and other related challenges associated with stratified medicine studies need to be harmonised. ${ }^{68}$ Compatibility of legal and regulatory frameworks and consistency in ethical committee standards that oversee these processes would also enable biobank networking initiatives and would facilitate drug efficacy and safety studies across different populations. ${ }^{67}$

In addition to inter-institutional sharing, data collected during clinical trials and through patient care pathways offers a unique and more complete understanding of individual health that would impact significantly on delivering stratified medicine studies. ${ }^{69}$ This could be achieved through efforts to integrate different layers of data, including molecular 'omics datasets, clinical phenotype data, knowledge of the environment that a person has been exposed to and citizen-contributed information. ${ }^{66,70}$ Investment is required in the fields of bioinformatics, biomathematics, and biostatistics to develop translational analyses of 'omics' data (see Table 1). ${ }^{70}$

Table 1. Glossary of related terms

\begin{tabular}{l|l}
\hline 'Omics" & $\begin{array}{l}\text { Areas of study within the field of biology generally associated with } \\
\text { large amounts of data, for example genomics, proteomics and } \\
\text { metabolomics }\end{array}$ \\
\hline Bioinformatics & $\begin{array}{l}\text { The application of methodologies and software tools to the } \\
\text { understanding of biological data }\end{array}$ \\
\hline Biomathematics & $\begin{array}{l}\text { The application of mathematical tools and techniques, and theoretical } \\
\text { analysis to investigate principles relating to living organisms }\end{array}$ \\
\hline Biostatistics & $\begin{array}{l}\text { The application of statistical methods to the design, analysis and } \\
\text { interpretation of biological experiments }\end{array}$ \\
\hline
\end{tabular}

One of the most active areas of research which is having an increasing impact on stratified medicine is the development of machine learning techniques for the analysis of large genomics and other data sets. Recent progress is likely to reflect the increasing availability of large well-curated data sets as well as the development of novel algorithms. A review by Librecht and Noble, noted the value of machine learning applications for analysis of genome sequencing data sets, including sequence annotation and epigenetic data. ${ }^{75}$

Exploiting digital platforms for identifying potential patients, trial set-up and design; empowering patients to be able themselves to be aware of a potential trial, ${ }^{76}$ self-consenting and enabling them to send in appropriate samples to a named investigator at a clinic would be a significant step forward. Other organisations have made that leap into mobilising public interest and activity through platforms such as the Apple research kit. ${ }^{77}$ 


\section{Cross-border working}

Research workforces that transcend organisational borders to recruit effectively and efficiently are critical to overcome the challenges of stratification arms and the paucity of patients that fit criteria of each arm, including the challenge of the large numbers of patients that require screening to recruit a sufficient number to satisfy inclusion/exclusion criteria. Amongst factors that hinder cross-border working include lack of standardisation of terminology and of data capture forms, requirements of metrics and reporting of individual organisations and networks.

Frequently there is regional and national variability in assessing the feasibility or more specifically evaluating the number of patients that will be eligible for a certain study at sites. This is of course not unique to stratified medicine studies, but affects all studies due to differences in staff expertise and experience, and process and time taken to make this assessment across different sites and regions. Feasibility of stratified medicine studies may be more complicated and require more time and effort because of the need to deeply phenotype patients, or ascertain genotype, to determine suitability for a particular arm. Better and more accurate ways of assessing feasibility are needed, and could for example include feasibility stages built into the trial design.

For effective research delivery, the fundamental point to address is how well research is embedded into healthcare provision and established patient pathways. ${ }^{78}$ The challenges associated with undertaking clinical trials in an environment which is naturally geared for clinical treatment delivery have been extensively catalogued by various stakeholders. ${ }^{79-81}$ Discernible progress has been made in the UK National Health Service, facilitated by dedicated research delivery networks, and the 100,000 Genome Project is providing valuable insights into how genomics can be embedded in clinical services. ${ }^{18}$ However, the specific complexities of stratified medicine research, which may not map neatly onto a specific clinical (diseasefocused) treatment pathway, pose significant challenges for recruitment which will need adaptation into how clinical research delivery networks work. ${ }^{82-84}$

Multi-stakeholder collaboration to accelerate the development and adoption of stratified medicine has been highlighted and recommended across many important reports. ${ }^{85-88}$ It is imperative that initiatives build on existing work undertaken and contribute to added value for all stakeholders involved.

\section{Conclusion}

Despite stratified medicine being part of political and health-related policy nationally and internationally over the last 5 years with significant investment from governments and industry, considerable challenges exist to undertaking a delivering stratified medicine research programmes. Addressing and agreeing a roadmap to tackle the key priority areas identified will enable the right support and training to be delivered to the workforce involved in undertaking stratified medicine studies.

Multi-stakeholder collaboration to accelerate the development and adoption of stratified medicine, highlighted and recommended across many important reports, has led to the creation of national and international consortia, including those present in the UK. These represent important drivers for the development of stratified medicine, but will continue to struggle to deliver, unless identification, phenotyping and recruitment of patients 
is optimised. These challenges are part of all forms of clinical research, but as we have highlighted, there are some key issues for stratified medicine, which make these studies even more difficult to deliver. It is also important to highlight that these challenges are not unique to studies which are academic in origin, but also affect industry-sponsored studies. It is important that these challenges are addressed effectively and promptly by clinical research networks that are well placed to support the delivery of these studies. Effective partnership at all levels, built upon experience and the availability of highly trained clinical research delivery staff, will be important to ensure that we can develop the evidence base necessary to implement novel treatments and clinical pathways to improve outcomes for patients.

\section{Acknowledgements}

The article is based on the findings of a workshop held by the UK Pharmacogenetics and Stratified Medicine Network www.uk-pgx-stratmed.co.uk/) and the NIHR Clinical Research Network in November 2016. We thank all those who attended and contributed in the workshop. ${ }^{89}$

\section{References}

1. European Science Foundation (ESF). Personalised Medicine for the European citizen - towards more precise medicine for the diagnosis, treatment and prevention of disease. European Science Foundation (ESF) Forward Looks. 2012

http://archives.esf.org/fileadmin/Public_documents/Publications/Personalised_Medicine.pdf(Accessed 07 Nov 2017)

2. Collins FS, Varmus H. A New Initiative on Precision Medicine. N Engl J Med. 2015 372:793-795.

3. DiPaolo A, Sarkozy F, Ryll B, Siebert U. Personalized medicine in Europe: not yet personal enough? BMC Health Services Research. 2017 17:289.

4. Day S, Coombes RC, McGrath-Lone1L, Schoenborn C, Ward H. Stratified, precision or personalised medicine? Cancer services in the 'real world' of a London hospital. Sociology of Health \& Illness. 2017 39:1:143-158. doi:10.1111/1467-9566.12457

5. Health economics for stratified medicine. The Academy of Medical Sciences. 2016 https://acmedsci.ac.uk/file-download/61141574 (Accessed 07 Nov 2017)

6. European Society for Medical Oncology. Ciardiello F, Arnold D, Casali PG et al. Delivering precision medicine in oncology today and in future - the promise and challenges of personalised cancer medicine: a position paper by the European Society for Medical Oncology (ESMO). Ann Oncol 2014 25 9:16731678. published 20 June 2014

7. Tiacci E, Park JH, De Carolis L et al. Targeting mutant BRAF in relapsed or refractory hairy-cell leukemia. N Engl J Med 2015 373:1733-1747

8. FDA Report. Paving the Way for Personalized Medicine: FDA's Role in a New Era of Medical Product Development. FDA Report. 2013

https://www.fda.gov/downloads/scienceresearch/specialtopics/personalizedmedicine/ucm372421.pdf . (Accessed 07 Nov 2017)

9. Ferrari N. Personalized Medicine A Canadian Funding Perspective. CIHR Institute of Cancer Research. http://www.ehfg.org/intranet/app/webroot/uploads/presentations/files/uploads/69a0e4e145f9835417d15b 1aa5a3e4.pdf (Accessed 07 Nov 2017) 
10. Anderson W. Genomic medicine in Australia. National Health and Medical Research Council.

https://www.genome.gov/multimedia/slides/gm6/18 warwick_anderson_australia.pdf (Accessed 07 Nov 2017)

11. Cyranoski D. China embraces precision medicine on a massive scale.

http://www.nature.com/news/china-embraces-precision-medicine-on-a-massive-scale-1.19108.

(Accessed 07 Nov 2017)

12. Reddy PJ, Jain R, Paik Y et al. Personalized Medicine in the Age of Pharmacoproteomics: A Close up on India and Need for Social Science Engagement for Responsible Innovation in Post-Proteomic Biology. Curr Pharmacogenomics Person Med. (2011) Mar 1; 9(1): 67-75. (Accessed 07 Nov 2017)

13. National Institutes of Health (NIH). About the Precision Medicine Initiative Cohort Program. Availablefrom: https://www.nih.gov/precision-medicine-initiative-cohort-program. (Accessed 07 Nov 2017)

14. Shaping Europe's Vision for Personalised Medicine. Strategic Research and Innovation Agenda. PerMed.

http://www.permed2020.eu/ media/PerMed SRIA.pdf (Accessed 07 Nov 2017)

15. Aktionsplan Individualisierte Medizin. Bundesministerium für Bildung und Forschung. https://www.leopoldina.org/uploads/tx_leopublication/2014_Stellungnahme_IndividualisierteMediz in_EN.pdf and http://www.gesundheitsforschung-bmbf.de/de/4950.php, website in German.

(Accessed 07 Nov 2017)

16. Plan France Médecine Génomique 2025. Aviesan.

http://aviesan.fr/en/aviesan/accueil/toute-1-actualite/plan-france-medecine-genomique-2025, website in French. The 'genomic medicine 2025' plan can be downloaded in English from this website.

(Accessed 07 Nov 2017)

17. NIHR Stratified Medicine Capabilities- Supporting innovation and expertise in stratified medicine.

http://www.nihr.ac.uk/life-sciences-

industry/documents/Brochures\%20and\%20flyers/NIHR_Stratified_Medicine_Capabilities brochure. pdf (Accessed 07 Nov 2017)

18. Stratified medicine in the NHS - An assessment of the current landscape and implementation challenges for non-cancer applications.

http://www.abpi.org.uk/our-work/library/medical-disease/Documents/stratified med nhs.pdf.

(Accessed 07 Nov 2017)

19. Keogh B. Personalised Medicine Strategy; NHS ENGLAND, Paper: PB.24.09.15/05. 2015

https://www.england.nhs.uk/wp-content/uploads/2015/09/item5-board-29-09-15.pdf. (Accessed 07

Nov 2017)

20. MRC Stratified Medicine Strategy Workshop Report. Medical Research Council. 2013

https://www.mrc.ac.uk/documents/pdf/stratified-medicine-strategy-workshop-report/. (Accessed 07

Nov 2017)

21. Institute of Medicine (US) Forum on Drug Discovery, Development, and Translation.

Transforming Clinical Research in the United States: Challenges and Opportunities: Workshop

Summary. Washington (DC): National Academies Press (US); 2010. 8, Building a Robust Clinical Trials Infrastructure https://www.ncbi.nlm.nih.gov/books/NBK50882/ (Accessed 07 Nov 2017) 
22. Denburg A, Rodriguez-Galindo C, Joffe S. Clinical Trials Infrastructure as a Quality Improvement Intervention in Low- and Middle-Income Countries. Am J Bioeth. 2016 Jun; 16(6):3-11.

23. Goldenberg NA, Daniels SR, Mourani PM et al. Enhanced Infrastructure for Optimizing the Design and Execution of Clinical Trials and Longitudinal Cohort Studies in the Era of Precision Medicine. J Pediatr. 2016 Apr; 171:300-6.e1-2.

doi: 10.1016/j.jpeds.2015.12.037. Epub 2016 Jan 16.

24. Hull MA, Yiannakou Y, Gower J, Ryder SD, Bloom SL, Rees CR. Getting involved in clinical trials research in the UK: how can Clinical Research Networks help? Frontline Gastroenterology. 2012; 3:66 -71.

25. Hanney S, Kuruvilla S, Soper B, Mays N. Who needs what from a national health research system: lessons from reforms to the English Department of Health's R\&D system Health Research Policy and Systems. 2010, 8:11

26. Stead M, Cameron D, Lester N. Strengthening clinical cancer research in the United Kingdom. British Journal of Cancer. 2011 104, 1529-1534. doi:10.1038/bjc.2011.69 www.bjcancer.com Published online 1 March 2011

27. Lythgoe H, Price V, Poustie V et al. NIHR Clinical Research Networks: what they do and how they help paediatric research. Arch Dis Child; 2017102 (8): 755-759.

28. Envisioning a Transformed Clinical Trials Enterprise in the United States: Establishing An Agenda for 2020. Workshop Summary. 3Improving Public Participation in Clinical Trials. Institute of Medicine (US). Washington (DC): National Academies Press (US), 2012 https://www.ncbi.nlm.nih.gov/books/NBK114660/

29. Kaye J, Curren, L, Anderson $\mathrm{N}$ et al. From patients to partners: participant-centric initiatives in biomedical research. 2012. Nature Reviews. Genetics, 13(5), 371-376. http://doi.org/10.1038/nrg3218

30. Vale C., Thompson L., Murphy C., Forcat S. and Hanley B. Involvement of consumers in studies run by the Medical Research Council (MRC) Clinical Trials Unit: Results of a survey, Trials. $201213,9$.

31. How to join in.

https://www.nihr.ac.uk/patients-and-public/how-to-join-in/. (Accessed 07 Nov 2017)

32. Smith SK, Selig W, Harker M et al. Patient Engagement Practices in Clinical Research among Patient Groups, Industry, and Academia in the United States: A Survey. 2015

PLoS ONE 10(10): e0140232. doi:10.1371/journal.pone.0140232

33. Domecq JP, Prutsky G, Elraiyah T et al. Patient engagement in research: a systematic review. BMC Health Serv Res. 2014; 14: 89. Published online 2014 Feb 26. doi: 10.1186/1472-6963-1489.

34. Forsythe LP, Szydlowski V, Murad MH at al. A Systematic Review of Approaches for Engaging Patients for Research on Rare Diseases. Hickam J Gen Intern Med. 2014 Aug; 29 (Suppl 3): 788-800. Published online 2014 Jul 22. doi: 10.1007/s11606-014-2895-9 PMCID: PMC4124116.

35. Patient and Public Involvement in the adoption of stratified medicine. Pharmacogenetics and Stratified Medicine Network. 2015

http://www.uk-pgx-stratmed.co.uk/images/stories/Participation.pdf (Accessed 07 Nov 2017)

36. Solomon BJ, Mok T, Kim D et al. First-line critzotinib versus chemotherapy in ALKpositive lung cancer. N Engl J Med 2014 371:2167-2177 
37. Korngiebel DM, Thummel KE, Burke W. Implementing Precision Medicine: The Ethical Challenges. Trends in pharmacological Sciences. 2017 January Volume 38, Issue 1, p8-14,

38. Kaplan R. The FOCUS4 design for biomarker stratified trials. Chin Clin Oncol 2015 4(3):35. doi: 10.3978/j.issn.2304-3865.2015.02.03

39. Chen P, Lin JJ, Lu CS et al. Carbamazepine-induced toxic effects and HLA-B*1502 screening in Taiwan. N Engl J Med 2011 364:1126-1133

40. Pirmohamed M, Kamali F, Daly AK et al. Trends Pharmacol Sci. 2015 36(3):153-63.

41. Impact of Patient, Carer and Public Involvement in Cancer Research. NCRN. 2012 October http://www.ncri.org.uk/wp-content/uploads/2013/07/2012-NCRI-PPI-report.pdf (Accessed 07 Nov 2017)

42. NHS England (London) participation and engagement report 2014/15.

https://www.england.nhs.uk/london/wp-content/uploads/sites/8/2015/12/ppv-london-2015.pdf

(Accessed 07 Nov 2017)

43. Wellcome Trust. How we engage the public.:

https://wellcome.ac.uk/what-we-do/our-work/public-engagement (Accessed 07 Nov 2017)

44. Impact of public involvement on the ethical aspects of research. HRA/Involve. 2016.

http://www.invo.org.uk/wp-content/uploads/2016/05/Impact-of-public-involvement-on-the-ethicalaspects-of-research-updated-2016.pdf (Accessed 07 Nov 2017)

45. Developing the Role of the Clinical Academic Researcher in the Nursing, Midwifery and

Allied Health Professions. Department of Health. 2012

https://www.gov.uk/government/uploads/system/uploads/attachment data/file/215124/dh_133094.p

df (Accessed 07 Nov 2017)

46. NIHR infrastructure. National Institute for Health Research.

https://www.nihr.ac.uk/about-us/how-we-are-managed/our-structure/infrastructure/ (Accessed 07

Nov 2017)

47. NIHR Medtech Capabilities. National Institute for Health Research. 2015

http://www.nihr.ac.uk/life-sciences-

industry/documents/Brochures\%20and\%20flyers/NIHR_Medtech_brochure.pdf (Accessed 07 Nov

2017)

48. Hawgood S, Hook-Barnard IG, O'Brien TC, Yamamoto KR. Precision medicine: Beyond the inflection point. Science Translational Medicine 7 (300), 300ps17. [doi: 10.1126/scitranslmed.aaa9970]

49. Williams MS, Ritchie MD, Payne PRO. Interdisciplinary training to build an informatics workforce for precision medicine. Appl Transl Genom. 2015 Sep; 6: 28-30.

50. Michelle D. Brazas, Fran Lewitter, Maria Victoria Schneider, Celia W. G. van Gelder, Patricia M. Palagi. A Quick Guide to Genomics and Bioinformatics Training for Clinical and Public Audiences. PLOS Computational Biology. 2014 April Volume 10, Issue 4. https://doi.org/10.1371/journal.pcbi.1003510

51. Darbyshire J, Sitzia J, Cameron D, Extending the clinical research network approach to all of healthcare. Annals of Oncology 22 (Supplement 7): vii36-vii43, 2011 chapter 6 doi:10.1093/annonc/mdr424

52. Research Ready Workforce.

http://www.nihr.ac.uk/life-sciences-industry/running-your-study-in-the-nhs/research-ready- 
workforce.html (Accessed 07 Nov 2017)

53. Sofosbuvir and Velpatasvir for HCV Genotype 2 and 3 infection. Foster GR, Afdhal N, Roberts SK et al. N Eng J Med 2015; 373: 2608-2617

54. Rawlins M, De testimonio: on the evidence for decisions about the use of therapeutic interventions. The Lancet. 2008 December Volume 372, No. 9656, p2152-2161,

55. Turner RM, Park BK, Pirmohamed M. Parsing interindividual drug variability: an emerging role for systems pharmacology. Wiley Interdiscip Rev Syst Biol Med. 2015 Jul-Aug;7 (4):221-41.

56. $\quad$ Chambers DA, Feero WG $\mid$ Khoury MJ Convergence of Implementation Science, Precision Medicine, and the Learning Health Care System: A New Model for Biomedical Research. JAMA.|(2016) May 10;315(18):1941-2. doi:10.1001/jama.2016.3867.

57. Ward DS, Vaughn AE, Burney RV, Østbye T, Recruitment of Family Child Care Homes for an Obesity Prevention Intervention Study. Contemp Clin Trials Commun. 2016 Aug 15;3:131-138. Epub 2016 May 9.

58. Elkhenini HF, Davis KJ, Stein ND et al. Using an electronic medical record (EMR) to conduct clinical trials: Salford Lung Study feasibility. BMC Med Inform Decis Malt 2015 Feb 7;15:8. doi: 10.1186/s12911-015-0132-z.

59. Hill JC, Whitehurst DGT, Lewis M et al. Comparison of stratified primary care management for low back pain with current best practice (STarT Back): a randomised controlled trial. Lancet 2011 378 (9802): 1560-1571.

60. Bushby K, Lynn S, Straub V. Collaborating to bring new therapies to the patient - the TREAT-NMD model. Acta Myol 2009) 28(1): 12-15.

61. The case for personalised medicine.

http://www.personalizedmedicinecoalition.org/Userfiles/PMC-

Corporate/file/pmc the case for_personalized medicine.pdf (Accessed 07 Nov 2017)

62. Biankin AV, Piantadosi S, Hollingsworth SJ. 2015. Patient-centric trials for therapeutic development in precision oncology. Nature, 526(7573), 361-370. DOI:10.1038/nature15819.

63. Health Research Authority. Our committees and services.

http://www.hra.nhs.uk/about-the-hra/our-committees/ (Accessed 07 Nov 2017)

64. Wellcome Trust. Understanding Patient Data launches today.

https://wellcome.ac.uk/news/understanding-patient-data-launches-today (Accessed 07 Nov 2017)

65. Zhang $\mid \mathrm{Y}$, Zhu $\mathrm{Q}, \mathrm{Liu}$ H. Next generation informatics for big data in precision medicine era BioData Min. (2015) 8: 34. doi: 10.1186/s13040-015-0064-2 PMCID: PMC4632361.

66. Stratified, personalised or P4 medicine: a new direction for placing the patient at the centre of healthcare and health education; Summary of a joint FORUM meeting held on 12 May 2015.

Supported by the Academy of Medical Sciences, the University of Southampton, Science Europe and the Medical Research Council https://acmedsci.ac.uk/file-download/38266-56e6d483e1d21.pdf. (Accessed 07 Nov 2017)

67. Gurwitz D, Zika E, Hopkins MM, Gaisser S, Ibarreta D. Pharmacogenetics in Europe: Barriers and Opportunities. European Commission Joint Research Center, Institute for Prospective Technological Studies, Seville, Spain. Public Health Genomic \$12009 12(3):134-41. doi:

$10.1159 / 000189625$.

68. Gligorijević V, Malod-Dognin N,Pržulj N Integrative methods for analyzing big data in precision medicine. Proteomic $\$$ |2016 Mar;16(5):741-58. doi: 10.1002/pmic.201500396. 
69. Beckmann JS, Lew D. Reconciling evidence-based medicine and precision medicine in the era of big data: challenges and opportunities. Genome Medicine 2016 8:134 DOI 10.1186/s13073-0160388-7.

70. Ping P, Watson K, Han J, Bui A, Individualized Knowledge Graph: A Viable Informatics Path to Precision Medicine. Circ Re\$. 2017 Mar 31;120(7):1078-1080. doi:

10.1161/CIRCRESAHA.116.310024.

71. "Omics". Wikipedia: The Free Encyclopedia. 27 Nov 2018 (accessed 07 Jan 2019); https://en.wikipedia.org/w/index.php?title=Omics\&oldid=870859185

72. "Bioinformatics". Wikipedia: The Free Encyclopedia. 02 Jan 2019 (accessed 07 Jan 2019); https://en.wikipedia.org/w/index.php?title=Bioinformatics\&oldid=876492304

73. "Mathematical and theoretical biology". Wikipedia: The Free Encyclopedia. 22 Dec 2018 (accessed 07 Jan 2019);

https://en.wikipedia.org/w/index.php?title=Mathematical and theoretical biology\&oldid $=874907698$

74. "Biostatistics". Wikipedia: The Free Encyclopedia. 28 Nov 2018 (accessed 07 Jan 2019); https://en.wikipedia.org/w/index.php?title=Biostatistics\&oldid=870953932

75. $\quad$ Libbrecht MW, Noble WS. Machine learning applications in genetics and genomics. Nature Reviews Genetics. 2015 June vol 16, 321-332

76. Lindemann M, Freeman T, Kilchenmann T._Patient Recruitment 2.0: Become a Partner in the Patient Journey Using Digital Media. JMIR Res Protoc. 2016 Jan-Mar; 5(1): e17. Published online 2016 Jan 27. doi: $10.2196 /$ resprot.5045.

77. Research Kit. Introducing ResearchKit.

http://researchkit.org (Accessed 07 Nov 2017)

78. Embedding research into the health system. The Academy of Medical Sciences. 2011.

https://acmedsci.ac.uk/file-download/34520-Jointbri.pdf (Accessed 07 Nov 2017)

79. $\quad$ Ross S,, Grant A, Counsell C, Gillespie W, Russell I, Prescott R, Barriers to participation in randomised controlled trials: a systematic review. J Clin Epidemio| || 1999 Dec;52(12):1143-56.

80. Current Issues in Clinical Trials. The Association of the British Pharmaceutical Industry. (2004) http://www.abpi.org.uk/our-work/library/medical-disease/Documents/clinical_trials.pdf (Accessed 07 Nov 2017)

81. Frank G. CURRENT CHALLENGES IN CLINICAL TRIAL PATIENT RECRUITMENT AND ENROLLMENT. SoCRA SOURCE. 2004

https://clinicaltrials.llu.edu/sites/clinicaltrials.llu.edu/files/docs/current-challenges-in-clinical-trialpatient-recruitment-and-enrollment.pdf (Accessed 07 Nov 2017)

82. $\quad$ Pritchard DE, Moeckel F, Villa MS, Housman LT, McCarty CA, McLeod HL. Strategies for integrating personalized medicine into healthcare practice. Personalized Medicine. March 2017 Vol. 14, No. 2, Pages 141-152, DOI 10.2217/pme-2016-0064 (doi:10.2217/pme-2016-0064)

83. Exemplar clinical pathways for a stratified approach to diabetes. Summary of a meeting held on 8 December 2015 by the Academy of Medical Sciences, and supported by NHS England. https://acmedsci.ac.uk/file-download/41569-57cfd3c90098c.pdf (Accessed 07 Nov 2017)

84. $\quad$ English V (ed). EUROPEAN COMMISSION Directorate-General for Research and Innovation Directorate E - Health Research Unit E.2. - Innovative and Personalised Medicine. Personalised Medicine Conference 2016 Report. Brussels. European Commission. 2016. 
https://ec.europa.eu/research/conferences/2016/permed2016/pdf/permed-2016_report.pdf(Accessed

07 Nov 2017)

85. Paving the Way for Personalized Medicine FDA's Role in a New Era of Medical Product Development. U.S. FOOD AND DRUG ADMINISTRATION. 2013

https://www.fda.gov/downloads/scienceresearch/specialtopics/personalizedmedicine/ucm372421.pdf

(Accessed 07 Nov 2017)

86. Realising the potential of stratified medicine. Academy of Medical Sciences. 2013

https://acmedsci.ac.uk/viewFile/51e915f9f09fb.pdf(Accessed 07 Nov 2017)

87. A Clarion Call for Creating a Global Precision Medicine Network.

http://www.thejournalofprecisionmedicine.com/wp-content/uploads/2016/10/October-2016-

Chagaturu.pdf. (Accessed 07 Nov 2017)

88. Shaping Europe's Vision for Personalised Medicine. Strategic Research and Innovation

Agenda. PerMed. 2015

http://www.permed2020.eu/ media/PerMed SRIA.pdf (Accessed 07 Nov 2017)

89. A Roadmap for Delivery of Stratified Medicine Research in the NHS. UK

Pharmacogenetics and Stratified Medicine Network 2016 http://www.uk-pgx-

stratmed.co.uk/index.php/november-2016-workshop-videos (Accessed 07 Nov 2017) 